\title{
Nuclear Medicine Technologist
}

National Cancer Institute

\section{Source}

National Cancer Institute. Nuclear Medicine Technologist. NCI Thesaurus. Code C53419.

A professional trained and certified in the field of medicine that utilizes the nuclear properties of radioactive and stable nuclides to make diagnostic evaluations of the anatomic or physiologic conditions of the body and to provide therapy with unsealed radioactive sources. The area of responsibilities of nuclear medicine technologist includes patient care (radiopharmaceuticals preparation and administration, use of radiation detection devices and other laboratory equipment to evaluate the quantity and distribution of radionuclides deposited in the patient or in a patient specimen, in vivo and in vitro diag nostic procedures, use of quality control and safety techniques), technical tasks, and administration. 